Article (refereed)

Carvalho, Laurence; Solimini, Angelo G.; Phillips, Geoff; Pietilainen, OlliPekka; Moe, Jannicke; Cardoso, Ana Cristina; Solheim, Anne Lyche; Ott, Ingmar; Sondergaard, Martin; Tartari, Gianni; Rekolainen, Seppo. 2009 Site-specific chlorophyll reference conditions for lakes in Northern and Western Europe. Hydrobiologia, 633 (1). 59-66. 10.1007/s10750-009$\underline{9876-8}$

(C) Springer Science+Business Media B.V. 2009

This version available http://nora.nerc.ac.uk/8053/

NERC has developed NORA to enable users to access research outputs wholly or partially funded by NERC. Copyright and other rights for material on this site are retained by the authors and/or other rights owners. Users should read the terms and conditions of use of this material at http://nora.nerc.ac.uk/policies.html\#access

This document is the author's final manuscript version of the journal article, incorporating any revisions agreed during the peer review process. Some differences between this and the publisher's version remain. You are advised to consult the publisher's version if you wish to cite from this article.

www.springerlink.com 


\section{Site-specific chlorophyll reference conditions for lakes in Northern \& Western}

\section{Europe}

Laurence Carvalho ${ }^{1}$, Angelo Solimini ${ }^{2}$, Geoff Phillips ${ }^{3}$, Olli-Pekka Pietiläinen ${ }^{4}$, Jannicke $\mathrm{Moe}^{5}$, Ana Cristina Cardoso ${ }^{2}$, Anne Lyche Solheim ${ }^{5}$, Ingmar Ott ${ }^{6}$, Martin Søndergaard ${ }^{7}$, Gianni Tartari ${ }^{8}$ and Seppo Rekolainen ${ }^{4}$

1 Centre for Ecology \& Hydrology (CEH), Bush Estate, Penicuik, Midlothian, EH26 0QB, UK. E-mail: laca@ceh.ac.uk

2 DG Joint Research Centre (JRC), Institute for Environment and Sustainability, European Commission, 21020 Ispra, VA, Italy

3 Environment Agency (EA), Kings Meadow House, Kings Meadow Road, Reading, RG1 8DQ, UK

4 Finnish Environment Institute (SYKE), Mechelininkatu 34a, P.O. Box 140, FI00251, Helsinki, Finland

5. Norwegian Institute for Water Research (NIVA), Gaustadalléen 21, NO-0349 Oslo, Norway

6. Estonian University of Life Sciences, Centre for Limnology, EE61117 Rannu Municipality, Tartu County, Estonia

7. National Environmental Research Institute (NERI), Aarhus University, Vejlsøvej 25, PO Box 314, DK-8600, Silkeborg, Denmark

8. Istituto di Ricerca Sulle Acque(IRSA), Via del Mulino, 19, 20047 Brugherio, Italy

Keywords: phytoplankton, lake, Water Framework Directive, WFD, baseline

This paper has not been submitted elsewhere in identical or similar form, nor will it be during the first three months after its submission to Hydrobiologia 


\section{Abstract}

The Water Framework Directive (WFD) requires EU Member States to assess the "ecological status" of surface waters. As a component of ecological status, many European countries are developing a classification scheme for chlorophyll concentrations as a measure of phytoplankton biomass. The chlorophyll classification must be based on the degree of divergence of a water body from an appropriate baseline, or 'reference condition'. This paper describes the development of a series of regression models for predicting reference chlorophyll concentrations on a sitespecific basis. For model development a large dataset of European lakes considered to be in reference condition, 466 lakes in total, was assembled. Data were included from 12 European countries, but lakes from Northern and Western Europe dominated and made up $92 \%$ of all reference lakes. Data have been collated on chlorophyll concentration, altitude, mean depth, alkalinity, humic type, surface area, and geographical region. Regression models were developed for estimating site-specific reference chlorophyll concentrations from significant predictor 'typology' variables. Reference chlorophyll concentrations were found to vary along a number of environmental gradients. Concentrations increased with colour and alkalinity, and decreased with lake depth and altitude. Forward selection was used to identify independent explanatory variables in regression models for predicting site-specific reference chlorophyll concentrations. Depth was selected as an explanatory variable in all models. Alkalinity was included in models for low colour and humic lakes and altitude was included in models for low colour and very humic lakes. Uncertainty in the models was quite high and arises from errors in the data used to develop the models (including natural temporal and spatial variability in data) and also from additional explanatory variables not considered in the models, particularly nutrient concentrations, retention time and grazing. Despite these uncertainties, site-specific reference conditions are still recommended in preference to type-specific reference conditions, as they use the individual characteristics of a site known to influence phytoplankton biomass, rather than adopt standards set to generally represent a large population of lakes of a particular type. For this reason, site-specific reference conditions should result in reduced error in ecological status classifications, particularly for lakes close to typology boundaries. 


\section{Introduction}

The estimation of reference conditions is considered crucial in many ecological assessment programmes (e.g. Moss et al., 1996; US EPA, 2000). These provide the baseline from which to determine change with time, and are necessary to evaluate a site's current status or potential for change. The European Water Framework Directive (WFD: Directive, 2000), also prescribes the use of reference conditions in the ecological status assessment of surface waters. As a component of ecological status, many European countries are developing a classification scheme for chlorophyll concentrations, as a relatively simple measure of water quality, in response to eutrophication pressures (e.g. Søndergaard et al., 2005). Type-specific chlorophyll reference concentrations have previously been established (Carvalho et al., 2008) and also agreed at a European level through an "Intercalibration" process (Poikane et al., 2009). The analysis, however, highlighted that even type-specific reference chlorophyll concentrations may not be ideal as the effects of certain typology factors, such as water colour and depth, on chlorophyll concentrations are continuous, and do not cause abrupt step-change differences between types (Carvalho et al., 2008). Sites that lie close to lake type boundaries may, therefore, be poorly represented by type-specific reference conditions and lead to large errors in any reference-based status assessment. Site-specific reference conditions may, therefore, be ecologically more appropriate and can be established simply from empirical regression models from a population of reference lakes (c.f. MEI model: Vighi \& Chiaudani, 1985; Cardoso et al., 2007). Another advantage of developing regression models for deriving site-specific reference conditions is that reference conditions could be established for lakes that do not fall strictly into the intercalibration lake types for which values have been agreed.

Furthermore a more quantitative understanding of how factors affect the natural background levels of phytoplankton chlorophyll in freshwater lakes is of interest to freshwater scientists in general. Regression models could be of potential value in predicting how water quality standards may be affected by future environmental changes, such as decreased levels of dissolved organic carbon in lake waters associated with climate change (Freeman et al., 2004) or reductions in acid deposition (Monteith et al., 2007) 
This paper describes the development of a series of regression models for predicting reference chlorophyll concentrations on a site-specific basis for lakes in Northern and Western Europe.

\section{Material and Methods}

\section{Criteria for reference lake selection}

Reference conditions are a state corresponding to low anthropogenic pressure on the whole water body. Reference lakes are not necessarily pristine, but must demonstrate only very minor effects of major industrialisation, urbanisation and intensification of agriculture in their catchment (CIS, 2003). What constitutes very minor pressure is open to debate. The selection of reference sites for this analysis was, however, carried out by individual Member States using agreed criteria laid down in WFD guidance (CIS, 2003). Further details of the criteria used and the comparability between Member States are documented in Carvalho et al. (2008). Additionally for this analysis, a threshold mean TP concentration of $100 \mu \mathrm{g} 1^{-1}$ was used as a final criterion, above which sites were removed from the analysis. This resulted in 5 sites (all with TP concentrations $>150 \mu \mathrm{g}^{-1}$ ) being excluded out of a total of 545 sites. The TP concentrations in the remaining dataset of 540 reference lakes were all lower than $70 \mu \mathrm{g}^{-1}$, with only three sites having concentrations $>50 \mu \mathrm{g}^{-1}$.

\section{Data}

Data from reference sites were collated on chlorophyll concentration, altitude, surface area, mean depth, alkalinity, colour and humic type. Lake data were gathered from national datasets from individual Member States through partners in the EC REBECCA Project (see http://www.environment.fi/syke/rebecca) and from EC and MS representatives involved in the Intercalibration process. Inevitably with such a large dataset of lakes from many countries there are questions over the quality of the data. To minimise sources of error in the dataset, lakes were only included in the analysis if they had three or more samples from different months between the period April to September (a 'growing period' in all lakes in the dataset). This is because previous analysis has shown that a single monthly sample is not sufficiently representative of an annual chlorophyll mean whereas bi-monthly or monthly 
sampling results in much less variable estimates (Clarke et al., 2006). If data from several years were provided for an individual lake, these growth season means were averaged over the years. If data from several sites within a lake were provided, these site means were averaged to give a whole lake mean, to ensure no bias was given to any particular lake in the model development. Additionally, sites were only included in the analysis for model building if measured depth and alkalinity data were available and at least information on humic type (low colour, humic or very humic) using colour criteria outlined in Van de Bund et al. (2004).

This resulted in a large dataset of 510 European lakes considered to be in reference condition, with 466 lakes having typology information suitable for developing the regression models. Data were included from 12 European countries, but lakes from Norway and Finland dominated and made up $82 \%$ of all reference lakes (Table 1). Despite the bias towards Northern and Western Europe (92\% of lakes), the dataset provides extensive coverage across a number of environmental gradients thought to be influential in determining background chlorophyll concentrations. High alkalinity lakes, were, however, poorly represented in the dataset, particularly deep or very shallow ones (Figure 1).

\section{Statistical analysis}

The relationships between chlorophyll concentrations and potential predictor variables (e.g. alkalinity, depth, altitude, area) were initially examined using simple boxplots and descriptive statistics by lake type. Lake types followed common agreed typologies in the intercalibration process (Van de Bund et al., 2004)

To derive models for estimating site-specific reference chlorophyll concentrations, we ran a General Linear Model (GLM) to estimate the best model to predict mean chlorophyll from several predictor variables. Altitude, alkalinity, mean depth, surface area and chlorophyll were all log transformed to normalize the data. Prior to the GLM, Pearson correlations were computed for each pair of variables to select the potential predictor variables. Lake area had a highly significant correlation with lake depth $\left(\mathrm{r}^{2}=0.36, \mathrm{p}<0.001, \mathrm{n}=502\right)$ and so was not considered further in the analysis in order to minimise the variance inflation factor. All the statistical analysis were performed with the statistics software SPSS (version 12, 2003) or Minitab (v14, 2005) 
Data on colour was provided in two forms: humic type (low, high or very high) or as measured colour data (Platinum units). Due to limitation of colour data from only 298 of the 540 lakes, regression models were developed for lakes of different humic type. Following development of these type-specific regression models, an Ftest was applied to examine whether type-specific regression lines were significantly different from each other and/or a global model.

Data were not generally available on analytical methods used for measuring chlorophyll. Of the five Member States providing information, all used spectrophotometric methods for routine monitoring. Extraction solvents and extraction time, however, varied both within, and between, Member States (ethanol, methanol or acetone extraction for 4-24 hours). Similarly, no information was available on whether or not an acidification step was used to correct for chlorophyll degradation products (pheophytin) and what equations were used to convert absorbance values to pigment concentrations. Of the two countries providing detailed methodologies (Estonia and Scotland), equations developed by Lorenzen (1967) and Jeffrey \& Humphrey (1975) were used, indicating an acidification step was incorporated.

\section{Results}

\section{Responses along environmental gradients}

Correlation analysis revealed significant relationships between log chlorophyll and $\log$ depth $\left(r^{2}=-0.494, p<0.001, n=505\right), \log$ colour $\left(r^{2}=0.481, p<0.001, n=298\right)$ and $\log$ alkalinity $\left(\mathrm{r}^{2}=0.213, \mathrm{p}<0.001, \mathrm{n}=497\right)$.

The strongest gradients were observed for depth and humic type. In terms of depth only, deep lakes generally had the lowest chlorophyll concentrations (median $1.9 \mu \mathrm{g} \mathrm{l}^{-1}$ ) and also showed the least variability, shallow lakes were intermediate (median $2.8 \mu \mathrm{g} \mathrm{l}^{-1}$ ) whilst very shallow lakes had the highest concentrations (median $7.3 \mu \mathrm{g}^{-1}$ ) and were also most variable (Figure 2). In terms of humic type, low colour waters had the lowest chlorophyll concentrations and showed the least variability (median $2.1 \mu \mathrm{g} \mathrm{l}^{-1}$ ), humic lakes were intermediate (median $4.1 \mu \mathrm{g} \mathrm{l}^{-1}$ ) whilst very humic lakes had the highest concentrations and were also most variable (median 11.6 $\mu \mathrm{g}^{-1}$ ) (Figure 3). Chlorophyll concentrations generally increased with increasing alkalinity although there were only slight differences in median values (and little 
difference in variability between alkalinity types (low alkalinity lakes: median $2.4 \mu \mathrm{g}$ $1^{-1}$; medium alkalinity lakes: median $3.2 \mu \mathrm{g} \mathrm{l}^{-1}$; high alkalinity lakes: median $3.4 \mu \mathrm{g}^{-}$ $\left.{ }^{1}\right)$. One exception of this pattern was for high alkalinity deep lakes, which showed lower chlorophyll concentrations than low and medium alkalinity lakes of this depth type (Figure 4)

Figure 5 illustrates for depth, how chlorophyll concentrations are a continuous response along this gradient and do not show any threshold response at type boundaries. Similar continuous responses were observed for colour and alkalinity.

\section{Regression analysis}

Approximately 200 of the 500 reference lakes were missing colour data, yet colour appeared to be a strong factor in determining reference chlorophyll concentrations. Of the 294 sites with colour data, 53\% were classified by member states as humic or very humic lakes. Of the 246 lakes with no available colour data, a very large proportion (71\%) was classified as low colour lakes. For this reason, it was decided to develop separate regression models for predicting site-specific chlorophyll reference conditions for lakes of different humic types and without using colour data as a predictor variable for low-humic waters.

Depth had a negative coefficient in all the regression models (Table 2). The other predictor variables selected differed between different lake types, although when selected had the same general effect (i.e. alkalinity was positive, altitude was negative). The best predictive model was produced for very humic lakes, although with an $r^{2}$ of 0.358 was still not high (Table 2).

\section{Discussion}

\section{Responses along Environmental Gradients}

Observations of chlorophyll concentrations in a large population of reference lakes, indicate that background or reference concentrations show a continuous response to a number of environmental gradients. No threshold responses, or step changes were apparent in scatterplots (e.g. Figure 5). This indicates that site-specific chlorophyll reference conditions, based on significant explanatory variables, are more appropriate 
than type-specific standards and should lead to less error in ecological status assessments.

Higher chlorophyll concentrations observed with decreasing depth were as expected, reflecting the well established positive relationship between algal biomass and light availability throughout the year (Sakamoto, 1966; Scheffer, 1998) and probably also due to the fact that deeper lakes generally have a higher water residence time and a lower nutrient loading per volume of water. Similarly, the increasing variability, or unpredictability, with decreasing depth presumably highlights the potential for much greater internal biotic control on phytoplankton production due to macrophyte and grazer control of phytoplankton in shallow lakes compared with deep lakes (Jeppesen et al., 1998). Very shallow lakes not only have very high potential for phytoplankton growth throughout the year, they also have the greatest potential for top-down limitation by zooplankton grazers and competition for light and nutrients with macrophytes. This may also be the explanation for the very shallow, high alkalinity lakes having lower chlorophyll concentrations than shallow and deep lakes of this same alkalinity type. The generally positive relationship between chlorophyll and alkalinity was, however, as expected, as it is well established that background nutrient availability is generally greater with increasing alkalinity (Dillon \& Kirchner 1975; Vighi \& Chaudani 1985; Cardoso et al., 2007).

Shifts in phytoplankton composition could be responsible for some of the gradients observed in chlorophyll. Chlorophyll content of cells varies between different algal taxa, for example cyanobacteria and diatoms have more accessory pigments and less chlorophylla per unit biovolume compared with Chlorophyta (Reynolds, 2006). Higher chlorophyll concentrations observed with increasing colour or humic type were not as originally expected, as it was envisaged that the reduced light availability in deeply coloured waters would reduce the potential for phytoplankton production. One reason for the observation may be because of compositional shifts in phytoplankton in very humic waters, with recognised shifts to large mixotrophic species, such as Gonyostomum semen (Arvola et al., 1999; Salonen et al., 2002). Additionally, phytoplankton have been shown become adapted to low light availability by producing more chlorophyll per unit biomass (Reynolds, 2006; Greisberger \& Teubner, 2007). 


\section{Regressions}

The regression equations incorporated coefficients that reflect the patterns observed along the environmental gradients, i.e increasing chlorophyll with increasing colour, decreasing depth and increasing alkalinity. Altitude was also a significant additional predictor in low humic lakes and borderline significant and included in model for very humic lakes. Increasing altitude being related to reduced chlorophyll concentrations, presumably due to lower temperatures and possibly also less nutrient availability in upland regions.

None of the regression models developed have a particularly strong predictive ability. This uncertainty may arise from two main sources:

1) Error / uncertainty in data used to develop regression models

2) Additional explanatory variables not considered in models

In terms of error in data used to develop the regression models, some of this may be due to sources of error associated with variable methods. It is widely recognised in particular that different solvents used for extraction of chlorophyll, for example acetone, ethanol or HPLC, all have variable extraction efficiencies, as does the timing, temperature and manner of extraction (Jacobsen \& Rai, 1990). To ensure comparable chlorophyll data across Europe, we strongly recommend standardised sampling, storage and analytical methods. Methods for measuring water colour and alkalinity for WFD typology purposes may also benefit from standardisation.

The variability in the data used to develop the models may, however, also have arisen from spatial and temporal variability in the water quality data. Strong seasonal, horizontal and, in deep lakes, vertical gradients in chlorophyll concentrations are typical in freshwater lakes (Small, 1963; Fee, 1976). Temporal variability was partly overcome by only considering lakes with three or more samples from different months in the period April to September only. It has, however, been shown that even regular monthly sampling (i.e. 6 samples from April to September) still produces an estimate of a mean chlorophyll concentration with a percentage SE of $14 \%$ for a shallow lake and 13\% for a deep lake (Clarke et al., 2007).

Uncertainty in the regression models may also be due to the fact that other important predictor variables were not considered in the models. Colour data were clearly lacking for many low humic lakes and water temperature was also not available. More importantly, however, key phytoplankton loss processes were not represented in particular no data were readily available on retention time, grazing and 
macrophyte coverage. We strongly recommend that retention time and water temperature are considered in future model developments. Both may help futureproof models for setting chlorophyll reference conditions under changing climatic regimes. Retention time has also long been recognised as one of the key variables in determining both nutrient availability and chlorophyll concentrations in lakes (Vollenweider \& Kerekes, 1982; Dillon, 1974). Another widely recognised driver of chlorophyll concentrations is nutrient availability. Despite the fact that the lakes were all considered as reference lakes, there was still variation in phosphorus and nitrogen concentrations and these are likely to be responsible for some of the variation observed. Whether this variation was due to slight differences in criteria used for reference site selection or differences in underlying geology, both result in varying levels of background nutrient concentrations.

Because of the bias in the dataset towards Northern and Western European low and medium alkalinity lakes, the models are not currently recommended for application to lakes in Central and Mediterranean regions of Europe where drivers of background productivity could be different. Further development of models for these regions is greatly limited by the lack of lakes in these regions that qualify as suitable reference lakes.

Despite these uncertainties, the analysis has revealed that site-specific reference conditions are generally recommended in preference to type-specific reference conditions, as they should result in reduced error in ecological status classifications, particularly for lakes close to typology boundaries; sites in the middle of the type range should be relatively unaffected. The approach may also be useful for Member States setting reference values for lakes that do not fall within agreed Intercalibration types, or Member States who have adopted more discrete typologies than some of the broad Intercalibration types.

\section{Acknowledgements}

This study was part-financed by the European Framework 6 Project REBECCA 'Relationships Between Ecological and Chemical Status of Surface Waters', Contract No.: SSPI-CT-2003-502158. We would like to thank our colleagues in the project, in particular those that supplied their data and those responsible for the database. We would also like to thank the GIG coordinator Sandra Poikane and GIG representatives and data providers for their cooperation and comments on aspects of the work. 


\section{References}

Anonymous, 2003. River and lakes - typology, reference conditions and classification systems. Guidance No 10. CIS Working Group 2.3 REFCOND, European Communities, Luxembourg.

Arvola, L., P. Eloranta, M. Järvinen, J. Keskitalo \& A.-L. Holopainen, 1999. Phytoplankton. In: Eloranta P. \& J. Keskitalo (eds.), Limnology of Humic Waters, Backhuys Publishers, Leiden: 137-171.

Cardoso, A. C., A. Solimini, G. Premazzi, L. Carvalho, A. Lyche Solheim \& S. Rekolainen, 2007. Phosphorus reference concentrations in European lakes. Hydrobiologia 584: 3-12.

Carvalho, L., A. Solimini, G. Phillips, M. van den Berg, O.-P. Pietiläinen, A. Lyche Solheim, S. Poikane \& U. Mischke, 2008. Chlorophyll reference conditions for European Intercalibration lake types. Aquatic Ecology 42: 203-211.

CIS, 2003. River and lakes - typology, reference conditions and classification systems. Common Implementation Strategy for the Water Framework Directive (2000/60/EC), Guidance document 10, European Commission, 86 pp. http://circa.europa.eu.

Clarke, R., L. Carvalho \& S. Maberly, 2006. Uncertainty in Chlorophyll and Total Phosphorus Classifications. In Carvalho L., G. Phillips, S. Maberly \& R. Clarke, Chlorophyll and Phosphorus Classifications for UK Lakes. Final Report to SNIFFER (Project WFD38), Edinburgh. http://www.sniffer.org.uk/

Dillon, P. J., 1974. A critical review of Vollenweider's nutrient budget model and other related models. Water Research Bulletin 10: 969-989.

Dillon, P. J. \& W. B. Kirchner, 1975. The effects of geology and land use on the export of phosphorus from watersheds. Water Research 9: 135-148.

Directive, 2000. Directive 2000/60/EC of the European Parliament and of the council of 23 October 2000 establishing a framework for community action in the field of water policy. Official Journal of the European Communities L 327: 1-72.

Fee, E. J., 1976. The vertical and seasonal distribution of chlorophyll in lakes of the Experimental Lakes Area, Northwestern Ontario: implications for primary production estimates. Limnology \& Oceanography 21, 767-783.

Freeman, C., N. Fenner, N. J. Ostle, H. Kang, D. J. Dowrick, B. Reynolds, M. A. Lock, D. Sleep, S. Hughes \& J. Hudson, 2004. Export of dissolved organic 
carbon from peatlands under elevated carbon dioxide levels. Nature 430: 195198.

Greisberger, S. \& K. Teubner. 2007. Does pigment composition reflect phytoplankton community structure in differing temperature and light conditions in a deep alpine lake? An approach using HPLC and delayed fluorescence (DF) techniques. Journal of Phycology 43: 1108-1119.

Jacobsen T. R. \& H. Rai, 1990. Comparison of spectrophotometric, fluorometric and high performance liquid chromatographic methods for determination of chlorophyll a in aquatic samples: Effects of solvent and extraction procedures. Internationale Revue der gesamten Hydrobiologie 75: 207-217.

Jeffrey, S. W. \& G. F. Humphrey, 1975. New spectrophotometric equations for determining chlorophylls a, b, c1 and c2 in higher plants, algae and natural phytoplankton. Biochemie und Physiologie der Pflanzen 167: 191-194.

Jeppesen, E., Ma. Søndergaard, Mo. Søndergaard \& K. Christoffersen (eds), 1998. The structuring role of submerged macrophytes in lakes. Springer Verlag, New York.

Lorenzen, C. J., 1967. Determination of chlorophyll and pheopigments: spectrophotometric equations. Limnology \& Oceanography 12: 343-346. Monteith, D. T., J. L. Stoddard, C. Evans, H. de Wit, M. Forsius, T. Hogasen, A. Wilander, B. L. Skelkvale, D. S. Jeffries, J. Vuorenmaa, B. Keller, J. Kopacek \& J. Vesely, 2007. Dissolved organic carbon trends resulting from changes in atmospheric deposition chemistry. Nature 450: 537-541.

Moss, B., P. Johnes \& G. Phillips, 1996. The monitoring of ecological quality and the classification of standing water in temperate regions: A review and proposal based on a worked scheme for British waters. Biological Review 71: 301-339. Poikane, S., M. van den Berg, J. Ortiz-Casas, G. Phillips, A. Lyche Solheim, D. Tierney, G. Wolfram \& P. Nõges, 2009. Lake assessment strategy in European Union (EU): Case study of European large lakes. Verhandlungen der Internationalen Vereinigung für Theoretische und Angewandte Limnologie 30 (in press).

Reynolds, C. S., 2006. Ecology of Phytoplankton. Cambridge University Press, Cambridge. 
Sakamoto, M., 1966. Primary production by phytoplankton community in some Japanese lakes and its dependence on lake depth. Archiv für Hydrobiologie 62: $1-28$.

Salonen, K., A.-L. Holopainen \& J. Keskitalo, 2002. Regular high contribution of Gonyostomum semen to phytoplankton biomass in a small humic lake. Verhandlungen der Internationalen Vereinigung für Theoretische und Angewandte Limnologie 28: 488-491.

Scheffer, M., 1998. Ecology of Shallow Lakes. Kluwer Academic Publishers, Dordrecht

Small, L. F., 1963. Effect of wind on the distribution of chlorophyll a in Clear Lake, Iowa. Limnology \& Oceanography 8: 426-432.

Søndergaard, M., E. Jeppesen, J. P. Jensen \& S. L. Amsinck, 2005. Water Framework Directive: ecological classification of Danish lakes. Journal of Applied Ecology 42: 616-629.

US EPA, 2000. Nutrient criteria technical guidance manual. Lakes and reservoirs. Environment Protection Agency, Office of Water and Technology, Washington DC.

Van de Bund, W., A. C. Cardoso, A.-S. Heiskanen \& P. Nõges, 2004. Overview of Common Intercalibration types. Electronic document. Publicly available at: http://wfd-reporting.jrc.cec.eu.int/Docs/typesmanual

Vighi M. \& G. Chiaudani, 1985. A simple method to estimate lake phosphorus concentrations resulting from natural, background, loadings. Water Research 19: 987-991.

Vollenweider, R. A. \& J. Kerekes, 1982. Eutrophication of waters. Monitoring, assessment and control. OECD Cooperative programme on monitoring of inland waters (Eutrophication control), Environment Directorate, OECD, Paris. 154 p. 


\section{Figure Legends}

Figure 1:

Scatter plot of reference lakes by depth and alkalinity gradients. Depth and alkalinity typology boundaries adopted by Intercalibration are indicated. [Depth types include very shallow ( $<3 \mathrm{~m}$ mean depth), shallow (3-15 m) and deep ( $>15 \mathrm{~m})$ lakes.

Alkalinity types include low $\left(<0.2 \mathrm{~m}\right.$. equiv. $\left.^{-1}\right)$, medium $(0.2-1.0)$ and high $(>1.0)$ alkalinity lakes]

Figure 2. Boxplots comparing chlorophyll reference conditions for very shallow $(n=59)$, shallow $(n=290)$ and deep $(n=156)$ lakes. See Figure 1 legend for definition of depth classes.

Figure 3. Boxplots comparing chlorophyll reference conditions for different humic classes of lakes (Low, n=311; Humic n=154; Very Humic n=41).

Figure 4. Boxplots comparing chlorophyll reference conditions for different depth and alkalinity classes of lakes. Based on data from 475 reference lakes.

Figure 5: Scatterplot of log Chlorophyll response against log mean depth 
Table 1: Numbers of reference lakes in dataset, by country

\begin{tabular}{lrr}
\hline Country & No. of lakes & \% of dataset \\
\hline Norway & 229 & $49.1 \%$ \\
Finland & 152 & $32.6 \%$ \\
Sweden & 31 & $6.7 \%$ \\
UK & 23 & $4.9 \%$ \\
Ireland & 10 & $2.1 \%$ \\
Poland & 7 & $1.5 \%$ \\
Netherlands & 4 & $0.9 \%$ \\
Estonia & 3 & $0.6 \%$ \\
Lithuania & 3 & $0.6 \%$ \\
Denmark & 2 & $0.4 \%$ \\
Germany & 1 & $0.2 \%$ \\
Italy & 1 & $0.2 \%$ \\
\hline
\end{tabular}

Table 2. Equation coefficients for predicting chlorophyll reference concentrations in European lakes.

\begin{tabular}{lrrrrrrr}
\hline Lake Type & N & Constant & log_Depth & log_Alkalinity & log_Altitude & log_Colour & $\mathbf{r}^{2}$ (adj) \\
\hline Low Colour & 282 & 0.855 & -0.165 & 0.131 & -0.111 & & $27.2 \%$ \\
\hline Humic & 137 & 1.193 & -0.317 & 0.336 & & & $27.9 \%$ \\
\hline Very Humic & 30 & -0.304 & -0.646 & & -0.476 & 1.295 & $35.8 \%$ \\
\hline Humic \& Very Humic & 167 & 1.205 & -0.442 & 0.176 & & & $25.3 \%$ \\
\hline
\end{tabular}

